\title{
Upaya Meningkatkan Brand Awareness NSR Skirt Melalui Strategi Komunikasi Pemasaran Media Sosial
}

\author{
Nur Sella Rakhmadhona \\ Postgraduate Programme, Institut Komunikasi dan Bisnis LSPR
}

\begin{abstract}
ABSTRAK
Fenomena pemasaran online berkembang seiring pertumbuhan penetrasi internet di Indonesia. Penerapan pemasaran media sosial (social media marketing) menambah dimensi baru untuk menyebarluaskan pesan, bertukar informasi tentang produk atau jasa, serta berbagi pengalaman mengenai suatu brand. Melihat peluang ini NSR, produsen pakaian jadi (garment) yang khusus memasarkan rok (skirt) secara daring (online) menggunakan konsep pemasaran media sosial (social media marketing) untuk membangun kesadaran merek (brand awareness) sekaligus meningkatkan penjualan produknya. Untuk membangun kesadaran merek NSR ini, membuat program pemasaran daring dengan menggunakan media sosial. Metode pengembangan program dilakukan dengan menerapkan model perencanaan pemasaran SOSTAC yang terdiri atas Situation Analysis, Objective, Strategy, Tactics, Action, dan Control (Smith, 2011). Perencanaan strategi pemasaran dalam membangun awareness dirancang pelaksanaannya selama kurun waktu enam bulan. Beberapa elemen yang menjadi kriteria untuk mencapai tujuan awareness menggunakan media sosial adalah jumlah likes, followers, hashtag dan viewer yang diikuti peningkatan pembelian.
\end{abstract}

Kata kunci: Media sosial; SOSTAC; awareness

\begin{abstract}
The phenomenon of online marketing is growing along with the growth of internet penetration in Indonesia. The application of social media marketing (social media marketing) adds a new dimension to disseminating messages, exchanging information about products or services, and sharing experiences about a brand. Seeing this NSR opportunity, manufacturers of apparel (garment) that specifically market skirts (online) use the concept of social media marketing (social media marketing) to build brand awareness (brand awareness) while increasing sales of its products. To build awareness of the NSR brand, create an online marketing program using social media. Program development methods are carried out by applying SOSTAC marketing planning models consisting of Situation Analysis, Objective, Strategy, Tactics, Action, and Control (Smith, 2011). Marketing strategy planning in building awareness is designed for implementation over a period of six months. Some elements that become criteria for achieving awareness goals using social media are the number of likes, followers, hashtags and viewers that are followed by increased purchases.
\end{abstract}

Keywords: Social Media; SOSTAC; awareness 


\section{PENDAHULUAN}

Fenomena pemasaran online berkembang seiring pertumbuhan penetrasi internet di Indonesia. Pada era global yang berkembang pesat ini jumlah pengguna internet di Indonesia terus tumbuh. Melalui internet masyarakat lebih dekat dan mudah untuk melakukan aktivitas, termasuk melakukan transaksi jual beli barang.

Data survei APJII memperkuat fakta bahwa internet kini menjadi wadah besar untuk bertransaksi secara online. Salah satu data yang sangat menarik adalah persentase dari internet sebagai tempat menawarkan atau mencari barang dan jasa sebanyak $98,6 \%$ atau sebanyak 130,8 juta pengguna internet. Pertumbuhan pengguna internet yang sangat pesat ini menjadikan internet sebagai saluran komunikasi yang efektif untuk memasarkan produk secara online.

Survei APJII (2016) mengungkap dari jenis konten yang diakses, pengguna internet Indonesia paling banyak menggunakan internet untuk mengakses media sosial $(97,4 \%)$, disusul untuk mencari hiburan (96,8\%), mengikuti berita $(96,4 \%)$, mencari informasi pendidikan $(93,1 \%)$, mengakses konten komersial $(93,1 \%)$, dan mengakses layanan publik $(91,6 \%)$. Dari sisi konten komersial yang dikunjungi, masyarakat paling banyak mengunjungi online shop (62\%), diikuti bisnis personal (34,2\%), dan konten komersial lainnya (3,8\%).

Survei di atas menunjukkan bahwa saat ini internet memiliki pengaruh penting terhadap dunia bisnis, terutama dalam hal komunikasi pemasaran, sebagai media komunikasi pemasaran yang efisien karena berbiaya rendah, namun sangat efektif karena mampu menjangkau khalayak yang sangat luas. Inilah salah satu implementasi konsep pemasaran low budget high impact, pendekatan pemasaran "di mana setiap sen uang yang dikeluarkan harus membawa dampak pemasaran yang setinggi mungkin" (Yuswohady, 2008).

Menurut Yuswohady, Low Budget High Impact adalah pendekatan pemasaran yang fokus pada biaya pemasaran berbiaya rendah tapi membuahkan hasil yang signifikan. Pendekatan ini diimbangi dengan pemilihan target pemasaran yang terarah, juga data survei yang kuat sehingga menjadi tepat sasaran dengan high impact.

Fenomena komunikasi pemasaran berbasis internet kini tidak lepas juga dari perkembangan media sosial, terutama Facebook dan Instagram. Kedua media sosial ini banyak beralih peran menjadi ajang e-dagang (e-commerce marketplace. Survei APJII (2016) menyebutkan bahwa Facebook menjadi media sosial yang paling sering dikunjungi dengan persentase $54 \%$, atau sebanyak 71,6 juta pengguna internet di Indonesia. Dan menyusul Instagram sebanyak 19,9 juta pengguna internet, dengan persentase $62 \%$ rata-rata pengguna internet adalah pengunjung onlineshop. Fakta tersebut membentuk peluang untuk membuka usaha onlineshop menggunakan media sosial yang kini paling banyak dikunjungi konsumen.

Salah satu online shop yang akan mencoba peluang tersebut ialah brand lokal NSR skirt, yang bergerak di bidang penjualan busana perempuan, khususnya rok, dengan menggunakan media sosial Facebook dan Instagram. Penggunaan media sosial ini bisa menjadi efektif dan ekonomis 
karena sesuai dengan metode yang akan digunakan dalam karya ini yaitu Low Budget High Impact. (Yuswohady, 2008).

Dalam proyek membangun brand awareness ini, objek yang diambil adalah NSR Skirt yang berdiri sejak tahun 2014, dengan spesialisasi pada produk yang hanya fokus pada busana rok. Pada awalnya pasar sasaran NSR Skirt sebatas masyarakat kelas menengah Kota Malang, Jawa Timur. Target pasar NSR Skirt adalah para wanita yang menggunakan busana rok sebagai identitas gaya mereka sendiri, dengan rata-rata usia 17-35 tahun, serta aktif menggunakan internet dan media sosial. Lebih khusus lagi, pada awalnya NSR Skirt membidik pasar kalangan para mahasiswi muslim di UMM Malang yang jumlahnya cukup besar melalui word of mouth dan media sosial. Melalui media sosial konten diisi dengan busana wanita yang sedang disukai, kemudian konsumen melakukan pemesanan menggunakan sistem pre-order (pesan di muka). Sistem pre-order ini diterapkan untuk meminimalkan produk yang tidak diminati, sehingga menghindari risiko kerugian akibat produk tidak terjual.

NSR menggunakan momentum kembalinya rok dalam trend busana belakangan ini. Mengutip dari artikel IDN TIMES, menyebutkan salah satu trend busana 2018 adalah pencil skirt, yakni busana bawahan berupa rok yang memiliki siluet lebar di bagian pinggang dan menyempit di bagian lutut. "Pencil skirt kembali menjadi tren tahun 2018. Kamu bisa menggunakan pencil skirt pada acara formal. Padukan dengan blazer agar penampilanmu semakin terlihat profesional. Kamu bisa pilih pencil skirt berwarna netral agar lebih mudah untuk mix and match".

Masalah yang diangkat dalam penulisan rencana kerja ini adalah Brand NSR telah vakum selama dua tahun. Setelah berjalan kurang dari satu tahun (2014-2015), kemudian NSR berhenti begitu saja pada 2016. Dalam rancangan karya ini penulis akan mengembangkan strategi komunikasi pemasaran untuk membangun kembali brand awareness NSR Skirt dengan menggunakan media sosial, karena internet kini menjadi alat bantu menyebar pesan yang sangat luas jangkauannya.

Perencanaan karya ini bertujuan untuk menyusun strategi komunikasi pemasaran untuk meningkatkan brand awareness NSR menjadi 120\% dalam waktu setahun dengan menggunakan media online, khususnya media sosial. Karya ini hanya mencakup perencanaan strategi untuk membangun brand awareness NSR Skirt melalui media sosial (social media marketing).

AISAS merupakan singkatan dari Attention, Interest, Search, Action dan Share. Dalam buku yang berjudul The Dentsu Way: Secrets of Cross Switch Marketing from The World's Most Innovative Advertising Agency, Sugiyama dan Andree (2011) mengatakan bahwa AISAS merupakan model komprehensif yang mengantisipasi perilaku beragam konsumen modern, serta di waktu yang sama berfungsi juga sebagai model yang beroperasi sesuai dengan kegiatan dunia nyata. Model AISAS bersifat nonlinear. Khalayak tidak selalu bergerak dari satu tahap ke tahap lain satu per satu, akan tetapi mungkin saja satu tahapan dapat terlewati atau mungkin diulang (Sugiyama \& Andree, 2011, p. 80). Sebagai contoh seseorang melihat iklan di televisi 
suatu produk kecantikan dan kemudian melakukan pembelian langsung ke toko nya (Attention $\rightarrow$ Interest $\rightarrow$ Action), atau seseorang yang menyukai seorang aktris lalu aktris tersebut muncul dalam iklan tutorial make up di internet dengan produk yang serupa sehingga membuatnya ingin membagi berita tersebut ke dalam sosial media sosial miliknya (Attention $\rightarrow$ Interest $\rightarrow$ Share). Dengan terbukanya sumber informasi melalui media online atau internet, kini manusia dapat duduk santai di depan gadget-nya mencari informasi yang diinginkan tanpa dihadapkan dengan iklan atau informasi sebelumnya.

Saat ini media sosial muncul di era digital yang kian pesat dan membuka peluang pebisnis untuk mulai membangun strategi komunikasi pemasarannya. Fenomena ini menjadi acuan penulis untuk menggunakan strategi low budget high impact yang digunakan penulis dalam perencanaan (Yuswohady, 2008).

Penerapan strategi low budget high impact ini diwujudkan dalam pemanfaatan media berbasis internet, terutama media sosial, yang sangat banyak penggunanya di Indonesia. Keberhasilan memanfaatkan media berbasis internet ini sangat erat kaitannya dengan kemampuan penerapan SEO dan SEM.

Menurut Kotler \& Amstrong (2012) bauran pemasaran merupakan seperangkat alat pemasaran yang digunakan perusahaan untuk terus menerus mencapai tujuan perusahaanya di pasar sasaran. Konsep bauran pemasaran menurut Kotler \& Keller (2012) terdiri dari 4P, yaitu product, price, place dan promotion. Adapun pengertian dari masing-masing bauran pemasaran adalah sebagai berikut: (1) Product, merupakan suatu yang dapat ditawarkan ke pasar untuk mendapatkan perhatian, agar produk yang dijual mau dibeli, digunakan atau dikonsumsi yang dapat memenuhi suatu keinginan dari konsumen.; (2) Price, merupakan sejumlah nilai yang ditukarkan konsumen dengan manfaat dari memiliki atau menggunakan produk atau jasa yang nilainya ditetapkan oleh pembeli dan penjual melalui tawar menawar, atau ditetapkan oleh penjual untuk satu harga yang sama terhadap semua pembeli.; (3) Place, tempat diasosiakan sebagai saluran distribusi yang ditujukan untuk mencapai target konsumen. Sistem distribusi ini mencakup lokasi, transportasi, pergudangan dan sebagainya.; (4) Promotion, yang berarti aktivitas yang menyampaikan manfaat produk dan membujuk pelanggan membelinya.; (5) Physical evidence, yaitu menunjukkan bahwa produk yang dibuat memang ada dan bisa dilihat melalui Instagram @NSR_Skirt.; (6) People, orang-orang yang terlibat di dalam proses produksi, layanan pelanggan dan pengiriman, hingga sampai kepada konsumen; dan (7) process, yakni proses produksi yang dilakukan untuk membuat produk NSR termasuk quality control.

\section{METODE PENELITIAN}

Perencanaan strategi komunikasi pemasaran membangun awareness ini dirancang kegiatannya dalam kurun waktu enam bulan, dengan memilih media sosial Instagram, Facebook, LINE dan 
WhatsApp sebagai alat penyebar pesan. Beberapa elemen membangun awareness antara lain jumlah viewers, likes, followers yang diiringi peningkatan penjualan.

Dalam perancangan strategi komunikasi yang dilakukan, maka digunakan metode perencanaan SOSTAC. Garis besar rencana komunikasi pemasaran sistem perencanaan SOSTAC, menurut Smith (2011), adalah daftar sederhana yang membantu para manajer mengingat komponen kunci dari sebuah rencana komunikasi pemasaran. Metode perencanaan SOSTAC terdiri dari Situation Analystic, Objective, Strategy, Tactics, Action and Control. Kegunaan metode SOSTAC di sini sebagai suatu metode secara bertahap agar lebih efektif menciptakan posisi yang strategis, sehingga dapat menghasilkan marketing plan yang efektif pada suatu perusahaan atau pemasaran suatu produk.

\section{HASIL DAN PEMBAHASAN}

Data Asosiasi Penyelenggara Jasa Internet Indonesia (APJII) menunjukkan pada 2017 87,13\% menunjukkan pengguna media sosial cenderung menyukai belanja daring. Sebanyak $48,57 \%$ pengguna media sosial di Indonesia adalah perempuan. APJII mengatakan aplikasi yang diunduh diponsel kebanyakan adalah aplikasi media sosial yang dikuasai oleh Instagram sebanyak 82,6\% dan Facebook 66,5\%.

Strategi yang digunakan selain menggunakan iklan di Instagram dan endorsement oleh influencer, taktik pemasaran juga menggunakan paidpromote. Taktik pemasaran endorsement ini direncanakan akan bekerjasama dengan influencer seperti Awkarin, Nazla Alifa juga Acha Sinaga. Alasan ketiganya dipilih selain karena memang mereka adalah influencer di media sosial dan memiliki jumlah followers yang tinggi, masing-masing memiliki karakter konten yang sama.

Awkarin (@awkarin) adalah selebgram perempuan 20 tahun yang memiliki khalayak umumnya para perempuan diatas 17 tahun. Nazla Alifa Sania (@nazlaalifa) adalah seorang perempuan berusia 21 tahun, dia juga seorang selebgram yang memiliki hobi travelling. Seluruh konten yang ia sebarkan menggunakan media sosialnya terlihat sangat rapi dan memiliki gaya yang unik. Kemudian ada Achsahinta Sinaga atau biasa di kenal Acha Sinaga (@achasinaga) perempuan berusia 29 tahun adalah aktris berkebangsaan Indonesia. Pembuat karya memilih Acha karena dalam usianya yang mewakili target pasar juga Acha sebagai Indonesian Style Influencer dianggap mampu mendorong minat komunikan untuk membeli produk NSR khususnya pada pekerja kantoran wanita.

Dalam projek yang dibangun untuk meningkatkan awareness ini penulis gunakan metode perencanaan SOSTAC, tahapan tersebut terdiri dari Situation Analysis, Objective Setting, Strategy, Tactic, Action, dan Control (Smith, 2011). Strategi komunikasi pemasaran yang dilakukan NSR menggunakan model AISAS (Sugiyama \& Andree, 2011), yang memaparkan proses mulai dari calon pelanggan sadar akan keberadaan merek (Awareness), kemudian tertarik (Interest), mencari informasi tentang produk (Search), membeli produk (Action), hingga membagikan pengalamannya (Share) kepada jejaringnya. 
Pada tahapan karya ini hal pertama yang dilakukan yaitu implementasi SOSTAC, untuk mengerti dan memahami lingkungan dan situasi pasar dilakukan analisis SWOT terhadap kondisi internal NSR. Kemudian membangun tujuan dan rencana kerja NSR, dalam hal ini membangun awareness yang dirumuskan menggunakan prinsip SMART (Specific, Measurable, Attainable, Relevant, Timbound). Ketiga yaitu mengatur strategi membangun kesadaran merek menggunakan media sosial yaitu, dengan mengatur konten sesuai dengan model puzzle feed. Dengan strategi mengatur feed seperti ilustrasi di atas, diharapkan NSR mampu mengarahkan asumsi komunikan tentang nilai-nilai fun dan fashionable terhadap brand NSR. Dalam membangun kesuksesan strategi dipilih elemen yang menjadi tolak ukur keberhasilan strategi yaitu, viewers, likes, followers. Kemudian yang keempat yaitu memilih taktik, yaitu bekerja sama dengan tiga influencer di Indonesia seperti Awkarin, Nazla Alifa dan Acha Sinaga. Pada agenda kegiatan pemasaran kerjasama yang dimaksud seperti iklan endors, paidpromote dan iklan di media sosial, akan dilakukan dalam kurun waktu tiga bulan dengan tema colorful.

Kemudian tahap selanjutnya yaitu konsumen melihat produk dan berkunjung ke media sosial NSR (viewer). Untuk mendorong action (pembelian) pembuat karya melakukan iklan secara intensif selama tiga bulan yang diiringi dengan iklan paidpromote juga iklan dari endorsment. Sementara mendorong khalayak turut membagikan (share) pesan, pembuat karya melakukan challenge yang berhadiah produk NSR di setiap minggu, yang tiap miggunya terdapat tiga orang pemenang.

Dengan metode SOSTAC ini diharapkan mampu merekonstruksi tahap demi tahap strategi yang digunakan dalam perencanaan membangun brand awareness, juga mampu mendeskripsikan perencanaan komprehensif dalam menganalisis strategi. Metode ini digunakan berdasar rencana pembuat karya yang ingin mengawali start up dengan membangun awareness terlebih dahulu melalui media sosial, dengan taktik menekan biaya promosi (low budget) dan memperluas target konsumen.

Pemasaran produk dimulai pada bulan September akhir 2018, yang akan disusul iklan menggunakan fitur Instagram $A d s$ dan Facebook $A d s$. Pada awalnya dilakukan pengaturan konten terlebih dahulu, kemudian disusun seperti puzzle feed untuk membangun citra sebelum akhirnya dilakukan endorsement, paidpromote, sales promotion dan juga iklan. Pada minggu awal peluncuran tiga product NSR telah mendapatkan total kunjungan profil atau viewers sebesar 67 viewers, dan 31 followers. 


\section{Gambar 1. Insight NSR Skirt di Instagram}
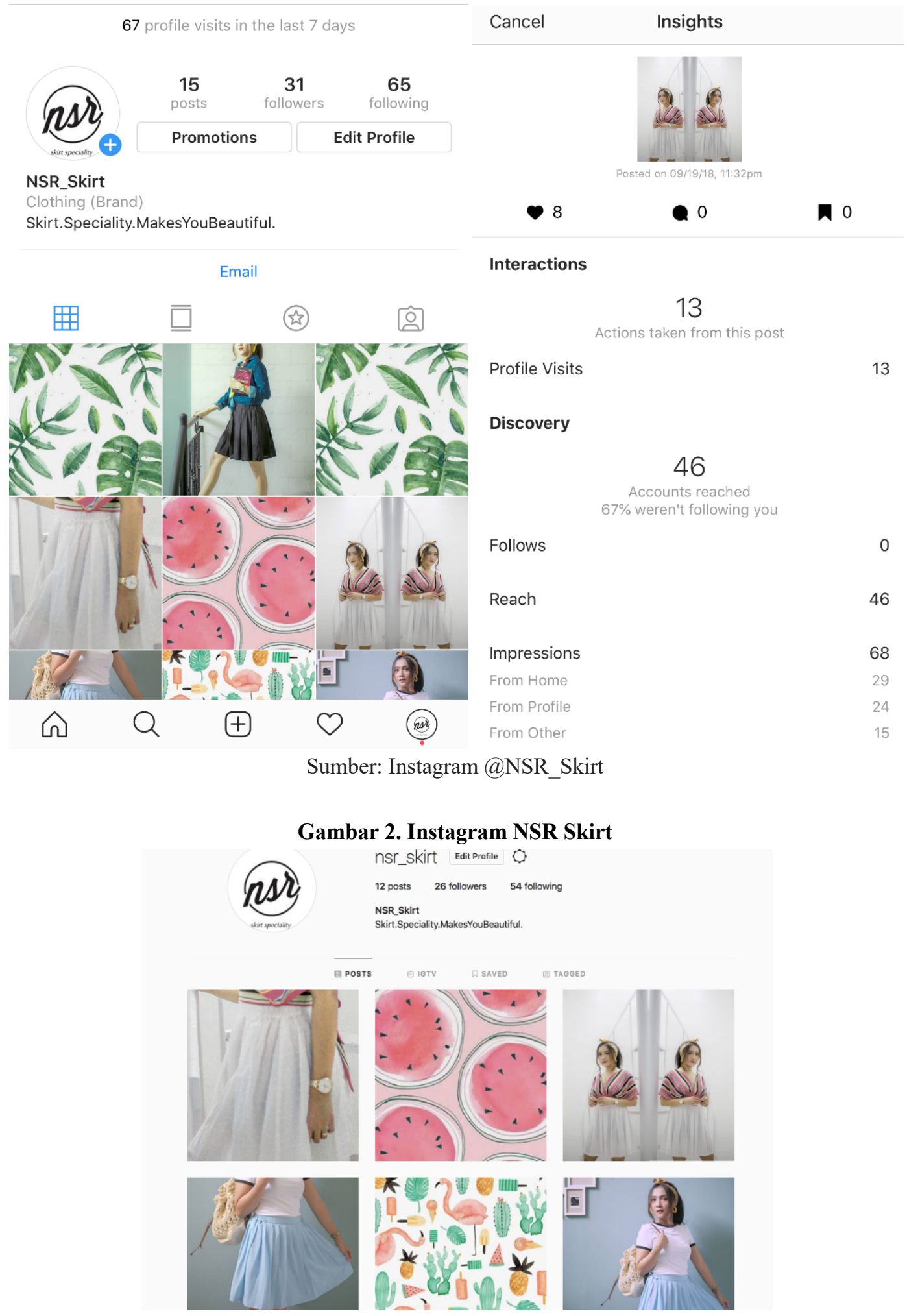

Sumber: Instagram@NSR_Skirt

Gambar 3. Facebook NSR Skirt 


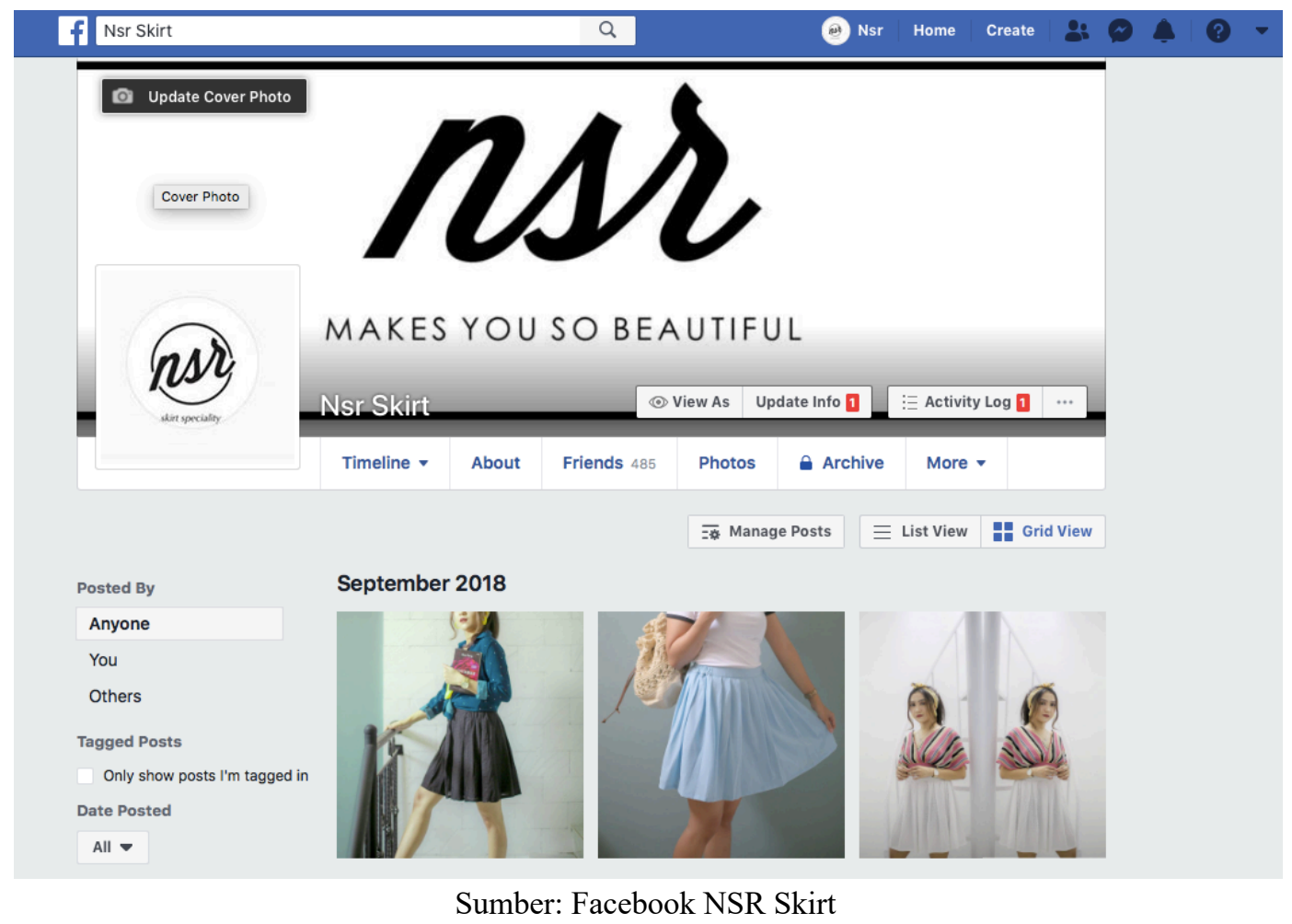

\section{SIMPULAN}

Project ini dirancang untuk membuat strategi pemasaran melalui social media marketing untuk brand NSR Skirt. Dengan mengimplementasikan perencanaan karya ini brand NSR Skirt akan mendapatkan brand awareness yang diiringi peningkatan jumlah viewers dan followers pada media sosial NSR skirt. Untuk meningkatkan brand awareness ini, selain mengembangkan media sosial sendiri, NSR juga menggunakan iklan di media sosial berupa fitur iklan Instagram dan Facebook Ads. Selain itu juga menggunakan jasa endorser, yakni Awkarin, Nazla Alifa dan Acha Sinaga. Dengan berbagai upaya ini brand awareness terhadap brand NSR diperkirakan akan melambung tinggi, sesuai dengan hukum Reed.

Dengan melihat unggahan konten NSR Skirt pada media sosialnya dan media sosial endorsernya, diharapkan khalayak sasaran akan tertarik (interest) dan mencari informasi (search) lebih lanjut. Untuk itu pembuat karya menerapkan SEO dengan menggunakan kata kunci (keywords) yang tepat, serta SEM dengan memasang iklan di media sosial, yakni di fitur Iklan Instagram dan Facebook Ads, selama tiga bulan. Pembuat karya juga menggunakan endorser untuk lebih menyebarluaskan pesan dan membuat khalayak sasaran mudah menemukan informasi tentang NSR. 


\section{DAFTAR PUSTAKA}

Aaker, D. (2011). Managing Brand Equity: Capitalizing on The Value of a Brand Name. The Free Press.

APJII (2017). Hasil Survei Penetrasi dan Perilaku Pengguna Internet Indonesia 2017. APJII. https://www.apjii.or.id/content/read/39/342/\%20Hasil-Survei-Penetrasi-dan-PerilakuPengguna-Internet-Indonesia-2017

Belch, G.E. \& Belch, M.A. (2009). Advertising and Promotion: An Integrated Marketing Communication Perspective. McGraw Hill.

Bunga, R. (2018, Januari 1). Pecinta Fashion Wajib Tahu Nih 10 Trend Busana di Tahun 2018. IDN Times. https://www.idntimes.com/life/women/rully-bunga/trend-busana-wanita2018-nanti/

Chaffey, D. (2009). E-Business and E-Commerce Management (4th ed.). Prentice Hall.

Chintamany, Y. (2019). Landasan Konseptual Perencanaan dan Perancangan Jogja Fashion Center di Yogyakarta (No. Publikasi 2971) [Skripsi Strata 1, Universitas Atma Jaya Yogyakarta]. UAJY's Library.

Evans, D. (2012). Social Media Marketing: An Hour a Day. Wiley Publishing.

Hertian, N. (2017, Januari 23). 6 Rok Fashion Generasi 90an yang Masih Trend Hingga Kini. ShopBack. https://www.shopback.co.id/katashopback/6-rok-fashion-generasi-90anyang-masih-trend-hingga-kini

Islamiyati, N. (2017, November 1). 10 Template Ini Akan Membantumu Membuat Instagram Story yang Ciamik. Jagoan Hosting_. https://www.jagoanhosting.com/blog/10template-ini-akan-membantumu-membuat-instagram-story-yang-ciamik/

Kotler, P. \& Keller, K.L. (2012). Manajemen Pemasaran (12th ed.). Erlangga.

Mahoney, M. L \& Tang, T. (2017). Strategic Social Media: From Marketing to Social Change. Wiley Blackwell.

Putri, A. (2012, Maret 23). Perkembangan Web. WordPress. https://aprilinaputri19.wordpress.com/2012/03/23/perkembangan-web

Rafiq, M., \& Ahmed, P. (1995). Using the 7Ps as a generic marketing mix: an exploratory survey of UK and European marketing academics. Marketing Intelligence \& Planning, 13(9), 4-15. https://doi.org/10.1108/02634509510097793 
Rangkuti, F. (2006). Analisis SWOT Teknik Membedah Kasus Bisnis. Gramedia Pustaka Utama.

Rangkuti, F. (2009). Strategi Promosi yang Kreatif dan Analisis Kasus Integrated Marketing Communication. Gramedia Pustaka Utama.

Regina, M., \& Pratama, S. (2015). Perencanaan Strategi Komunikasi Pemasaran Sababay Winery Melalui Online Marketing [Tidak Diterbitkan, Skripsi Strata 1]. STIKOM The London School of Public Relations - Jakarta.

Setiadi. (2003). Perilaku Konsumen: Konsep dan Implikasi untuk Strategi dan Penelitian Pemasaran. Prenada Media.

Smith, P.R. \& Zook, Z. (2011). Marketing Communication: Integrating offline and online with social media (5th ed.). Kogan Page.

Sugiyama, K. \& Andree, T. (2011). The Dentsu Way: Secrets of cross switch marketing from the world's most innovative advertising agency. McGraw Hill.

Tracy, L.T. (2008). Advertising 2.0: Social Media Marketing in a Web 2.0 World. Praeger Publishers.

Watson, T. \& Noble, P. (2005), Evaluating Public Relations: A Best Practice Guide to Public Relations and Evaluation. Kogan Page.

WEBARQ Digital Agency (2016, September 15). Memahami SEO dan SEM Bagi Pemula Digital Marketing. WEBARQ. https://www.webarq.com/id/memahami-seo-dan-sembagi-pemula-digital-marketing.html

Wicaksono, K. C. B. (2013). Mengukur Efektivitas Social Media Bagi Perusahaan. Binus Business Review, 4(1), 551-564. https://doi.org/10.21512/bbr.v4i1.1419

York, A. (2018, Maret 13). Best Times to Post on Social Media: 2018 Industry Research. Sprout Social. https://sproutsocial.com/insights/best-times-to-post-on-social-media/

Yuswohady. (2008, September 6). "Low Budget High Impact” Marketing. Yuswohadi.com. https://www.yuswohady.com/2008/09/06/\%E2\%80\%9Clow-budget-highimpact $\%$ E2\%80\%9D-marketing/ 